Artigo

\title{
Hiperativismo pedagógico
}

\section{Pedagogical hyperactivism}

Hiperactivismo pedagógico

\author{
Luana Rafaela da Silva Costa ${ }^{1}$ \\ (D) [0000-0003-1091-8985] \\ Simone Moura Queiroz ${ }^{2}$ \\ [0000-0002-3878-4619]
}

\begin{abstract}
Resumo
Esta pesquisa apresenta uma discussão sobre o movimento discursivo consolidado no ensino de matemática, pois, se por um lado sempre existiu uma corrente discursiva sobre a dificuldade na disciplina, percebe-se um novo movimento, constituído de discursos, práticas, métodos e prescrições por acreditar que esses são capazes de reverter e tornar a matemática mais interessante e acessível. Aproxima-se das contribuições teóricas das escritas sobre discurso de Foucault, bem como algumas considerações de autores do campo da Educação Matemática, propomos pensar sobre a desestabilização das verdades que circulam nesse campo. Tramas que foram construídas através de entrevistas envolvendo dois professores e dois alunos nessa dinâmica social, produtora de saberes, poderes e verdades enquanto processo de fabricação de uma docência dada, conduzindo a pensar a singularidade dos sujeitos professores. Dessa maneira, evidenciou como os sujeitos são efeitos discursivos, reverberando e pondo em práticas os saberes materializados em documentos curriculares que se tornam práticas pedagógicas.
\end{abstract}

Palavras-chave: Educação Matemática. Filosofia da Diferença. Discurso. Práticas Pedagógicas. Hiperativismo Pedagógico.

\begin{abstract}
This research presents an discussion about the consolidated discursive movement in the teaching of mathematics, because, if on the one hand there has always been a discursive current about the difficulty in the discipline, one perceives a new movement, consisting of discourses, practices, methods and prescriptions because one believes that these are able to reverse and make mathematics more interesting and accessible. It approaches the theoretical contributions of Foucault writings on discourse, as well as some considerations of authors in the field of Mathematics Education, we propose to think about the destabilization of the truths circulating in this field. Dialogue built through interviews involving two teachers and two students in this social dynamic, producer of knowledge, powers and truths as a process of manufacturing a given teaching, leading to thinking about the uniqueness of the teaching subjects. This manner showed how subjects are discursive effects, reverberating and putting into practice the knowledge materialized in curriculum documents that become pedagogical practices.
\end{abstract}

Keywords: Mathematics Education. Philosophy of Difference. Discourse. Pedagogical Practices. Pedagogical Hyperactivism.

1 Ir.luanarafaela@gmail.com, Mestre em Educação em Ensino de Ciências e Matemática, Quipapá/PE/Brasil.

2 simonemq35@gmail.com, Doutora em Educação Matemática, Docente, Universidade Federal de Pernambuco/UFPE/CAA, Caruaru/PE/Brasil. 


\begin{abstract}
Resumen
Esta investigación presenta una discusión sobre el movimiento discursivo consolidado en la enseñanza de las matemáticas, porque, si por un lado siempre ha existido una corriente discursiva sobre la dificultad de la disciplina, se percibe un nuevo movimiento, consistente en discursos, prácticas, métodos y prescripciones porque se cree que éstos son capaces de revertir y hacer más interesantes y accesibles las matemáticas. Nos acercamos a las aportaciones teóricas de los escritos sobre el discurso de Foucault, así como a algunas consideraciones de autores en el campo de la enseñanza de las matemáticas, nos proponemos pensar en la desestabilización de las verdades que circulan en este campo. Evidencias construidas a través de entrevistas que involucraban a dos profesores y dos estudiantes en esta dinámica social, productora de conocimientos, poderes y verdades como proceso de fabricación de una enseñanza determinada, que lleva a pensar en la singularidad de los temas de enseñanza. De esta manera se demostró cómo los sujetos son efectos discursivos, reverberando y poniendo en práctica los conocimientos materializados en documentos curriculares que se convierten en prácticas pedagógicas.
\end{abstract}

Palabras claves: Educación Matemática. Filosofía de la diferencia. Discurso. Prácticas pedagógicas. Hiperactivismo pedagógico.

\title{
1 Primeiros delineamentos
}

Como se manter motivado(a) para estudar matemática? Como tornar a matemática mais atraente? Como descomplicar a matemática? Aprenda matemática em 10 passos. Métodos para ensinar matemática melhor, etc. Essas indagações e afirmações são comuns para professores, pais de alunos, estudantes e até mesmo outros interessados pela disciplina escolar. Enquanto há um movimento discursivo de dificuldade e restrição em relação a matemática escolar, há um movimento contrário, que busca métodos, técnicas e prescrições, ou seja, há uma prática discursiva e pedagógica em busca de reverter os discursos negativos em relação a disciplina.

Nessa perspectiva apresentamos esse recorte da dissertação A BUSCA POR ALGO NOVO E SOBRETUDO SINGULAR: estratégias que possibilitem rupturas aos entrelaçamentos discursivos em relação à prática docente em matemática, a qual buscou investigar essa construção discursiva e seus efeitos em relação a matemática enquanto componente curricular, diante das considerações sobre as diversas práticas pedagógicas destinadas ao ensino da matemática. Utilizando como principal referencial teórico as contribuições sobre discurso de Foucault (2008) entre outros autores da educação matemática realizando essa interseção.

Faz-se interessante mencionar que Foucault não realizou seus estudos em relação aos discursos especificamente voltados à educação, e não inauguramos esse debate, existem algumas pesquisas direcionadas a esse campo. Fischer (2001), por exemplo, realizou um diálogo exemplificando conceitos de discurso com a educação, enfatizando as relações entre mídia e adolescência. Há outras produções envolvendo a influência discursiva e a educação, como Veiga-Neto (2007), Sartori e Duarte (2015), entre outras que possibilitam pensar as relações entre Foucault e a educação. Dessa maneira, buscamos descrever e problematizar discursos sobre a dificuldade em matemática e sua possível reversão colocadas como verdades pelas práticas pedagógicas.

Para a discussão temática, neste artigo, apresenta-se o surgimento das verdades sobre o ensinar matemática na contemporaneidade, apresentando sua materialidade presente nos 
documentos normativos curriculares e reverberados pelos sujeitos da educação. $\mathrm{Na}$ sequência, como essa materialização se alia aos desafios enfrentados pelos professores, prescrevendo "métodos eficazes", determinando uma docência dada. Constituindo uma verdade no campo de ensino da disciplina, acarretando em um hiperativismo pedagógico, que parece totalizar práticas, enfatizando apenas a eficácia, contribuindo para uma compreensão de modelo infalível e como essa prática discursiva mobiliza a prática pedagógica.

\section{Discurso e práticas pedagógicas}

Para Foucault (2008) investigar um discurso seria pensá-lo como uma verdade constituída na sociedade, sendo esse resultado de um processo social e cultural de cada tempo, resultando efeitos nos sujeitos. O discurso para o autor segue regularidades, e colocam em funcionamento a produção de conhecimentos, o sentido as coisas, as práticas sociais e a consolidação de verdades. Essas regularidades, são compostas por procedimentos que permitem diferenciar um discurso aceitável ou não, diante de uma sociedade legitimadora de discursos que autoriza determinados sujeitos a pronunciarem a "verdade" enquanto desautoriza outros (FOUCAULT, 2013). Nessas perspectivas fomos norteadas pela indagação, como funciona a legitimação dos discursos sobre prática pedagógica no ensino de matemática?

Ainda segundo Foucault (2008) o discurso se consolida diante de um conjunto de enunciados, apoiados em uma mesma formação discursiva. Essa formação discursiva, apresenta-se como campo normativo que determina aquilo que pode e deve ser dito dentro de um determinado espaço, além de outras regulações nem sempre visíveis, normatizando a legitimação e aceitação de determinado saber. Nessa perspectiva, o discurso integra o enredo do poder, por carregar certo regime de verdade. Esses discursos, essas verdades ganham materialidade, seja por meio da escrita, do desenho, da pintura, da música, dos livros, dos documentos oficiais, entre outros. A materialidade não é apenas seu aspecto visível, mas a forma que se apresenta, que organiza e distribui esses discursos.

Um dos efeitos dos discursos consolidados sobre a dificuldade em matemática e a necessidade de mudança é a "[...] naturalização que a saída para uma disciplina acessível depende da prática de ensino, produzindo sua dispersão a ponto de implicar efeitos de verdades e produção de prática no campo da matemática escolar" (COSTA; QUEIROZ, 2019, p. 2). As regularidades discursivas responsabilizam as práticas docentes por acreditar que essas podem modificar esse panorama de dificuldade em relação à disciplina. "[...] Ingredientes necessários e os modos de preparo da mistura que proporcionaria aos alunos uma degustação perfeita da aula de um bom professor de matemática" (AURICH; PINHO, 2012, p. 6).

Certamente, definir algo como verdade está estabelecido como uma relação de poder, em síntese, os significados sempre estão ligados no discurso, numa relação, tentando impor seus valores. As obras foucaultianas apontam para a compreensão de como as verdades constituídas transformam-se a partir dos saberes e poderes de cada época e como causam efeitos sobre os sujeitos, atribuindo a eles um modo de ser. "O discurso nada mais é do que a reverberação de uma verdade nascendo diante de seus próprios olhos; e quando tudo pode, enfim toma a forma de discurso [...]" (FOUCAULT, 2013, p. 46).

Cada sociedade tem seu regime de verdade, sua "política geral" de verdade: isto é, os tipos de discurso que ela acolhe e faz funcionar como verdadeiros; 
os mecanismos e instâncias que permitem distinguir os enunciados verdadeiros dos falsos, [...] o estatuto daqueles que têm o encargo de dizer o que funciona como verdadeiro (FOUCAULT, 2000, p. 12).

Dessa maneira, nasce um discurso validado, autorizado, produzindo uma verdade sobre a utilização de recursos para ensinar matemática, essa importância passa a ser legitimada pelos documentos oficiais, como os Parâmetros Curriculares Nacionais para a matemática. A presença dos PCN no cenário educacional brasileiro tem início no ano de 1995, diante das sucessivas reformas sobre o ensino de matemática, dessa maneira, as secretarias municipais e estaduais buscam adequar-se às normas vigentes. Esses documentos operacionalizados pelo poder do Estado, visam normatizar e subsidiar o trabalho docente, as relações de poder exercidas nos documentos provenientes do Estado acabam produzindo efeitos de verdade que produzem as práticas docentes.

Fischer (2001, p. 207) afirma que, "[...] ao analisar um discurso mesmo que o documento considerado seja a reprodução de um simples ato de fala individual, não estamos diante da manifestação de um sujeito, mas sim, nos defrontando com um lugar de sua dispersão e de sua descontinuidade". Assim, devemos nos perguntar: Que novas políticas de verdades estão sendo postas? Que novas políticas de verdades irão ser construídas? De modo geral, os PCN apontam para um lugar idealizado de referência para o professor "atualizado". Para Oliveira (2007), os parâmetros propõem uma revisão de um currículo na busca de uma escola inovadora, expressando em seu conjunto uma verdade acerca do saber produzido na escola. Mais que isso, um conjunto de saberes instituídos por uma determinada política. Os $\mathrm{PCN}$, com isso, orientam práticas curriculares que definem regras e atribuem valores, determinando como o conhecimento deve ser selecionado e organizado, indicando uma forma, uma maneira de como o professor pode adequar sua prática e sua conduta no espaço da sala de aula.

O documento esclarece sobre a importância do ensino e aprendizagem da matemática desde a Educação Infantil ao Ensino Médio em diferentes versões, dessa forma, constituem um conjunto de verdades que são propostos sobre a formação de professores, sobre currículos escolares e sobre as metodologias consideradas mais adequadas em relação às outras e que possibilitem esse conhecimento de maneira prazerosa para ao aluno.

Encontra-se os alunos rodeados pela força discursiva que potencializa a resistência de aproximar-se da disciplina, e espera-se que os professores criem caminhos contrários a esse fluxo, que busquem maneiras de romper, subverter essa potência discursiva negativa, defendida socialmente e sugerem como fazer. Surgem também outras regras, modelos sobre como ensinar. "Imersos a tantas docências previamente nomeadas e pré-dadas, professores mergulham e afogam-se em suas prescrições que acabam por conduzir sua ação pedagógica dentro e fora do espaço institucional escolar" (AURICH, 2017, p. 15).

\section{Entrelaçando discussões}

Buscamos descrever a consolidação das práticas pedagógicas como reversão aos discursos negativos em relação a matemática, dados produzidos por meio de entrevistas com quatro participantes, dois professores e dois alunos. Para manter o anonimato, nossos participantes foram nomeados da seguinte forma, os professores Hi-tech e Reflexivo, e os alunos Introvertido e Dedicada, os nomes resultaram de uma característica marcante da 
personalidade dos sujeitos, o que não anula a existência de outras características ou que, algumas vezes, assumissem outros comportamentos. Observe o diálogo abaixo.

Pesquisadora: O que vocês consideram como uma boa aula de matemática?

Reflexivo: Uma aula que faça com que o aluno tente enxergar a matemática não apenas como uma disciplina mecânica e chata. Que ele consiga indagar sobre os diversos tipos de uso da matemática. Hi-tech: Ser prática, direta, utilizando se possivel tecnologias e ferramentas matemática.

Pesquisadora: Quais recursos didáticos mais utilizados por você?

Hi-tech: Quadro, livro didático e jogos.

Reflexivo: Eu também, quadro, livro, jogos e materiais manipuláveis.

Pesquisadora: Considerando sua experiência como aluno e hoje como professor, vocês conseguem perceber alguma mudança no ensino da disciplina de matemática?

Reflexivo: Consigo, acho que hoje a gente consegue ter mais acesso à tecnologia, também facilitou muita coisa, e a gente consegue ter mais materiais manipuláveis, usar algum tipo de programa para que o aluno possa ver.[...] eu acho que essa mudança foi positiva. Antes era muito tradicional, hoje ainda é tradicional, mas antigamente era mais.

Hi-tech: Eu notei, principalmente de maneira geral. A etnomatemática e o ensino da matemática ajudaram os professores aprender a aprender e melhoraram o ensinar matemática através dessas novas tecnologias no ensino de matemática.

Pesquisadora: Esses matérias manipuláveis, a tecnologia, o uso de recursos didáticos em geral, tem melhorado o ensino de matemática?

Hi-tech: Jogos, materiais manipuláveis e tecnologias, sim. Estes despertam o interesse dos alunos para o ensino da matemática.

Reflexivo: Eu acho que melhora, eu acho que faz com que o aluno, ele fique mais curioso, faz com que ele perceba que aquilo existe. Que não é uma invenção de alguém que pensou e disse... é desse jeito. Então, eu acho que ele consegue pensar, realmente isso existe, então, aquela fórmula saiu de tal lugar, é por isso que a área é calculada desse jeito...

Pesquisadora: Como são as aulas de vocês?

Reflexivo: São aulas expositivas, pois o material disponibilizado pela escola não colabora para que haja uma aula mais dinâmica.

Hi-tech: A maioria são tradicionais, porque tem que ensinar todo conteúdo, por causa das provas externas, não dá para sempre fazer algo diferente. É porque é uma burocracia, os laboratórios, a maioria dos computadores não funcionam, também quando levamos os alunos para lá, demora tempo organizando e o tempo da aula vai embora. A internet também não ajuda.

Reflexivo: Também já desisti de realizar coisas na sala por causa da burocracia.

Pesquisadora: Como vocês planejam suas aulas?

Reflexivo: Videoaulas, internet...

Hi-tech: Uma aula tradicional planejo com o livro, nem sempre dá para fazer, planejar uma aula, dou sequência no livro. Mas, quando quero fugir desse tradicionalismo e o assunto permite, pesquiso na internet, tem muita atividade boa.

(Diálogo com professores, 2019).

Tendo compreendido o discorrido pelos professores, fizemos a mesma pergunta aos alunos a respeito de uma boa aula de matemática:

Pesquisadora: Para vocês, o que seriam uma boa aula de matemática? A ponto de sair dizendo "nossa, essa aula foi show!".

Introvertido: Uma aula que ensine coisas novas, uma boa explicação, passo a passo.

Dedicada: Imagino uma aula mais divertida.

Pesquisadora: Como seria essa aula mais divertida? 
Dedicada: É, não sei. Espera, tipo, que o professor trouxesse brincadeiras com a matemática, acho que é bem legal, jogos.

Pesquisadora: Vocês gostam de jogos? Com eles vocês aprendem mais?

Dedicada: Sim... com certeza! Porque você fica concentrado no jogo, porque você quer ganhar tanto que acaba se dedicando no jogo.

Introvertido: O objetivo é ganhar.

Pesquisadora: Os professores que vocês já tiveram até hoje, traziam esses recursos para sala de aula?

Introvertido: Sim. Já trouxeram formas geométricas em 3D, teve uma vez que um trouxe uma balança, outras vezes a gente já fez brincadeiras de matemática.

Dedicada: Foi bem legal, porque você está se divertindo e aprendendo.

Pesquisadora: E para vocês, como seria um bom professor de matemática?

Introvertido: Aquele que dá uma aula explicando as coisas certas, mesmo sendo um assunto novo, difícil, o importante é ensinar direito e fazer brincadeira também, para não ficar muito chato.

Dedicada: Um professor divertido que interage com os alunos, brinca, explica passo a passo $e$ quando você não entende, explica de novo, sem reclamar.

(Diálogo com estudantes, 2019).

Nas falas dos professores e alunos aparecem frequentemente o uso de recursos didáticos como uma saída para o ensino de matemática, ainda que não a utilizem constantemente. Há um consenso que os recursos didáticos são importantes, porém os professores continuam utilizando o livro didático com mais frequência, e para os alunos uma boa aula está mais pautada no ensino adequado, paciente, uma boa explicação do que nos recursos em si. Oliveira (2007, p. 45) aponta o seguinte questionamento.

[...] o que é dito sobre os processos de aprender e ensinar matemática são discursos que produzem significado, o qual passa a ter efeito de verdade por meio de incorporação de estratégias que sugerem um modo correto de se fazer matemática nas escolas. Isso se dá através de dispositivos que entram em operação para produzir discursos como efeitos de verdade sobre aquilo que nomeiam. $O$ que é definido como verdadeiro deve ser entendido como um problema de poder, pois os significados nunca flutuam livremente no discurso. Eles movimentam-se num contexto de relações que tentam impor seus valores. Além disso, nos termos de Foucault, um conjunto de práticas discursivas e não-discursivas, consideradas em suas conexões com relações de poder, formam dispositivos.

Segundo Castro (2009), Foucault reconheceu que faltava em seus trabalhos em que predominava a arqueologia, a análise do poder, a relação entre discurso e não discurso. Com isso, desenvolveu o conceito de dispositivo, a qual passa a ser objeto de descrição na genealogia, passando a dedicar-se a estudar os variados mecanismos estratégicos que, por sua vez, dificultam perceber o que falam os elementos que os constituem. De acordo com Foucault (2000, p. 244), dispositivo é:

[...] um conjunto decididamente heterogêneo que engloba discursos, instituições, organizações arquitetônicas, decisões regulamentares, leis, medidas administrativas, enunciados científicos, proposições filosóficas, morais, filantrópicas. Em suma, o dito e o não dito são elementos do dispositivo. $O$ dispositivo é a rede que se pode tecer entre estes elementos. 
Inferimos o quanto não existe uma característica geral, fixa de dispositivo, até porque sua forma, sua estrutura não é o elemento mais importante, mas a relação existente entre os elementos heterogêneos que exerçam funções subjetivadoras. Há uma série de práticas e mecanismos que têm a finalidade de obter respostas a um objetivo estratégico, intervindo de modo racional sobre um campo de forças em que se insere, com o intuito de determinar certa direção, atendendo as funções para quais foi criado e, dessa forma, impedir outras que se diferenciem. A descrição deleuziana sobre um dispositivo o descreve como "[...] uma espécie de novelo ou meada, um conjunto multilinear" (DELEUZE, 1990, p. 155). Palavras aplicadas diante da descrição proposta às inúmeras linhas, podendo serem amarradas, dobradas, emaranhadas, rompidas, etc. São linhas de naturezas diferentes que dão estrutura ao dispositivo, podendo esse ser caracterizado por maneiras heterogêneas, uma rede composta por estruturas físicas ou não, essas linhas se aproximam, afastam-se, mesclam-se, se rompem, são submetidas em favor da intencionalidade do dispositivo, reconfigurando-se sempre que necessário.

Dessa maneira, o conjunto de textos, prescrições, constatam-se a presença de estratégias discursivas atuando como dispositivos de verdades, credenciando a utilização de recursos como uma saída possível para o ensino e aprendizagem em matemática, dispositivo incorporado por vozes de sujeitos autorizados pelos documentos normativos. Esses documentos normativos podem ser considerados dispositivos, pois agem diante de um conjunto de estratégias e em busca de um determinado fim. Assim como a escola também é um dispositivo, repleto de normas e regimentos, assim como a licenciatura. De modo geral, o sujeito professor está inserido em muitos dispositivos, que visam moldá-lo e, por vezes, esses visam moldar seus alunos.

O discurso da Educação Matemática é formado por diversos enunciados, inclusive, os discursos de mudanças sobre o ensino da disciplina. Ao atentarmos aos enunciados, não podemos buscar um sentido final, nem mesmo o que o enunciado esconde, mas atentarmos ao dito e seus efeitos. Esse dito revela os enunciadores, pesquisadores e educadores matemáticos, sejam eles estudantes de licenciatura em matemática ou pedagogia, estudante de pós-graduação, mestres ou doutores, são autores em diferentes condições, em espaços de discussões, inclusive, de outros autorizados para nesse contexto que satisfazem certas exigências. Pois, "[...] ninguém entrará na ordem do discurso se não satisfazer a certas exigências ou se não for, de início qualificado para fazê-lo" (FOUCAULT, 2013, p. 37).

Pesquisadora: Você acredita que essa concepção dos recursos didáticos foi uma contribuição da universidade ou você foi percebendo que essa utilização seria interessante?

Reflexivo: Eu acho que foi a universidade. Acho que se eu não tivesse entrado nunca na universidade e pedissem um dia para eu dar uma aula, eu acho que eu iria pegar um lápis e escrever no quadro somente. Não ia pensar em nada diferente. Acho que a universidade tem seus defeitos, mas ela abre muito a mente da gente professor em relação a esse tipo de questionamento.

Hi-tech: Eu fiz uma pós-graduação e também formações sobre ensino da matemática, que me ajudaram a repensar e dar uma sacudida no meu caminhar pedagógico.

(Diálogo com professores, 2019).

Cada sociedade tem seu regime de verdade, ou seja, uma "sociedade de discurso", como denominado por Foucault, produz discursos que circulam em espaços fechados, conforme determinadas regras, no caso da Educação Matemática, os congressos, encontros, simpósios, etc. inclusive nas graduações e pós-graduações, nos quais são organizados uma 
materialidade discursiva e que fazem circular essas "verdades" (SARTORI; DUARTE, 2015). O discurso é um formador de subjetividade e a verdade é aquilo que cada um considera como verdadeiro.

Pensar no professor hoje, evidencia uma concordância de pensamentos vinculados ao período que ele está inserido, uma formação discursiva. Para isso, temos referências governamentais e acadêmicas, que lhe atribuem o poder para serem considerados formadores de opinião e referenciais produtores de verdade. Discursos que levam a compreensão da matemática, do docente e sobre ela circular. Por tempos, uma tendência pedagógica surge a fim de contemplar aquilo que a anterior não deu conta, e nessa enxurrada de informações, encontra-se os professores, antigos e novos, uns conduzidos pelo aprender, outros em busca de se atualizarem, imersos a tantas docências, encontram-se no hiperativismo sócio virtual e pedagógico.

\section{Hiperativismo sócio virtual}

No século XVIII, Foucault (2005) demonstrou como as instituições (fábricas, hospitais, presídios, escolas, hospícios, quartéis) operam em confinamento (distribuição dos indivíduos dentro do espaço), disciplina (docilidade do corpo) e vigilância (punição). Seus estudos não se voltaram especificamente à educação, a escola aparece ao apresentar as semelhanças entre essas instituições, fatores responsáveis por denominar a dinâmica social como sociedade disciplinar. O foco dessas instituições seria um melhor funcionamento pautado na ordem. Um corpo era considerado produtivo se respondesse aos anseios da instituição, apresentando uma boa performance, considerando o uso correto do tempo, do espaço e do próprio corpo.

Nesse âmbito, a noção de ordem está muito próxima das técnicas disciplinares. Teve-se com elas, a partir do uso delas o sonho de uma sociedade perfeita. Uma sociedade em ordem, no qual, o menor desvio fosse detectado. É todo um investimento do detalhe que se fez. O poder disciplinar é o poder que se ocupa do detalhe do ínfimo. Nada deve passar despercebido; pelo contrário, tudo deve ser observado (BATISTA; BACCON e GABRIEL, 2015, p. 12).

Deslocando essa compreensão para a educação atual, ainda é possível analisar esses mecanismos. Temos os indivíduos enfileirados na entrada, nos pátios e na sala, voltados para aquele que mantém a vigilância e a ordem, onde os alunos deverão ser produtivos, respondendo as atividades e assimilar uma sucessão de assuntos ensinados e pelos quais serão avaliados, geralmente em silêncio, no tempo correto das aulas. A punição pode ser feita por meio de provas, recuperação e reprovações, além de serem constantemente vigiados contra o uso do celular ou algo que seja proibido naquele espaço. Tudo com exatidão, aplicação e regularidade.

Segundo Deleuze (2013), vivemos uma transição da sociedade disciplinar para a sociedade do controle. Entretanto, cada sociedade põe em funcionamento suas sujeições. Os procedimentos disciplinares ficaram cada vez mais cautelosos e continuaram com suas funções de docilizar e adestrar os sujeitos, que são constantemente vigiados, acabando por adequar-se ou desterritorializar-se diante das normas que são estabelecidas.

A escola é uma instituição disciplinar, entretanto, essa instituição eficaz para manter o poder tem perdido sua eficácia quanto a essa finalidade, pois, à medida em que se tem relações de poder, têm resistências, muitas das alternativas ou tentativas de renovação das 
instituições escolares não tem dado respostas urgentes às demandas da crise escolar, por vezes entendida como desordem na instituição, fazendo muitos sujeitos, inclusive pais e professores, questionar e defender o poder disciplinar que "funcionou bem" em seu tempo. Segundo Brígido (2013), os dispositivos utilizados pela sociedade se justificam pelo poder para domesticação dos corpos, afirmando a necessidade da vigilância e da punição. "Esses dois dispositivos são inseridos na sociedade de forma discreta, chegando a um ponto na construção da sociedade que a existência desses dispositivos é vista como necessária, indispensável e legitima pelos próprios cidadãos" (BRÍGIDO, 2013, p. 56)

É preciso desprender-se do poder na concepção repressiva, da ordem contra o caos, e pensar o caos como produtivo, gerador de novos saberes, deslocando e provocando reflexões e possibilidades (BRÍGIDO, 2013). Para Deleuze (1996), conforme citado por Catto (2010, p. 40), "[...] somos feitos de linhas que se arquitetam em nossas vidas e não param de e entrelaçar. Linhas duras, linhas maleáveis e linhas de fuga". Essas linhas variam entre duras e maleáveis, diante da força aplicada nelas, possibilitando dobrá-las. A escola sempre foi constituída como linha dura, disciplinar, porém, é preciso repensar esse papel.

Aproximando-se dessa temática, foi pedido a Hi-tech que desenhasse o lugar que menos gosta na escola, tivemos os seguintes resultados.

Figura 1 - Desenho do lugar que Hi-Tech menos gosta na escola

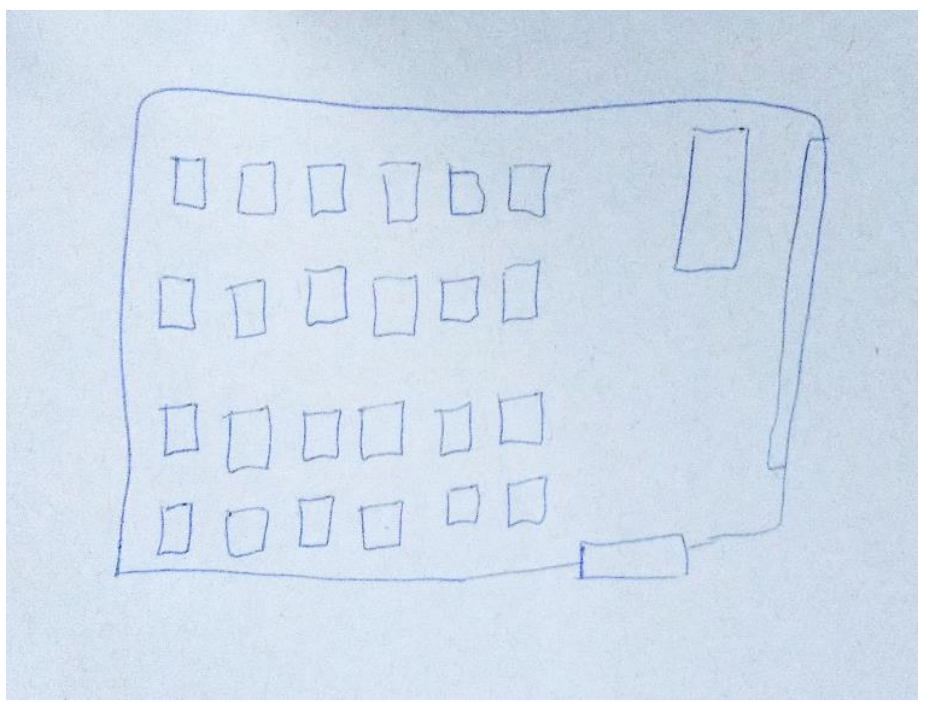

Fonte: Acervo da pesquisa, 2019.

Hi-tech: A sala de aula, à tarde.

Pesquisadora: É o lugar que você menos gosta?

Hi-tech: É, são muitos alunos e o barulho. Eu gosto de dar aula, mas às vezes a indisciplina é grande. Eles não colaboram, às vezes, tenho a sensação de estar dando aula para dois ou três alunos, que estão ali, copiando. Os outros conversam muito. Eu chamo atenção, eles fazem silêncio, mas logo depois voltam a conversar.

Pesquisadora: Por que acha que isso acontece? O que você gostaria de fazer para mudar isso? Hi-tech: Não sou fã de escola militar, mas regras mais rígidas ajudariam a educação no todo. Já a matemática também melhoraria com o acréscimo das novas tendências e da mudança da mentalidade dos professores, ainda presos no Ensino Fundamental.

Pesquisadora: Você acha que criar mais regras é uma saída? 
Hi-tech: Sim, como disse, não como a escola militar, mas regra para o aluno se comportar, disciplina. Às vezes, ele não quer aprender, mas acaba atrapalhando aquele que quer, e tem muitos assuntos, e também tem as provas externas.

Pesquisadora: Você se sente mais cobrado por ensinar a disciplina de matemática em relação as outras disciplinas?

Hi-tech: Um pouco, pela importância da disciplina e peso nas provas externas, mas deveria ser igual para todas as disciplinas.

(Diálogo com professores, 2019).

Nesse contexto, encontramos as escolas, as quais têm sofrido severas críticas, pois apesar das mudanças constantes na sociedade, os sistemas educacionais têm demonstrado resistência, mesmo sendo considerado falho para preparar e orientar os sujeitos a conviver na modernidade líquida (BAUMAN, 2000).

E em meio a toda esta complexidade encontramos os sujeitos da educação, alunos e professores, cada qual com sua multiplicidade, seus desejos. Tendo que interagir em um ambiente que muitas vezes em vez de agenciá-los, faz com que eles optem por rotas de fugas, por desterritorializar-se existencialmente (QUEIROZ, 2016, p. 2).

De acordo com Batista, Baccon e Gabriel (2015), houve um enfraquecimento das técnicas disciplinares, na medida que se tem uma forte insubmissão a elas, ou seja, uma resistência para atender o que tem sido pedido, seja pelo descomprometimento das atividades solicitadas, seja pelo abandono escolar, ou seja, como afirmou Queiroz (2016), por manter-se na sala, mas desterritorializar-se existencialmente. "Eis que alguém poderia questionar: vocês afirmam que o desleixo dos alunos, no fundo é um tipo de resistência? Não sabemos talvez [...]" (BATISTA; BACCON e GABRIEL, 2015, p. 12). Essa nova dinâmica posta pelos comportamentos dos alunos, tem gerado muitas discussões na tentativa de reverter esse desinteresse.

Pesquisadora: Qual sua opinião sobre a consideração comum da matemática difícil?

Hi-tech: Acho que os alunos têm um déficit de aprendizagem e a evasão escolar, que causam desinteresse em matemática e faz o efeito bola de neve para o resto da vida, geralmente.

Pesquisadora: Qual o seu papel enquanto professor de Matemática, tendo em vista esses desafios em relação à disciplina?

Hi-tech: Meu papel é mostrar a matemática como ela é, objetiva, prática e usada nas coisas mais simples da vida.

Pesquisadora: E o que você faz para mostrar isso?

Hi-tech: Para despertar é preciso utilizar novas tecnologias e tendências de ensino de matemática.

Pesquisadora: A utilização desses recursos tem surtido efeito? Ou já proporcionou uma experiência marcante ao ensinar matemática?

Hi-tech: Sim, tive que me adaptar às tecnologias e tendências no ensino de matemática para acompanhar o novo aluno. Faz cinco anos que aconteceu isso.

Pesquisadora: O que seria esse novo aluno?

Hi-tech: Esse aluno conectado, que sabe tudo de tecnologia, que só vive no celular.

Pesquisadora: Eles gostam quando você utiliza esses recursos na sua aula?

Hi-tech: Gostam, mas não é sempre que dá para fazer, tem conteúdo que não dá. Outro problema é que quando liberamos a internet para a utilização de algum aplicativo, ou de um programa, muitas vezes, percebemos o aluno no Facebook, no WhatsApp, e deixam de lado o 
objetivo da aula, o professor tem que ficar em cima, são poucos que fazem o que é pedido, aí o conteúdo se perde.

Pesquisadora: Como você se sente quando isso acontece?

Hi-tech: Desmotivado, aí penso era melhor a aula tradicional mesmo, pelo menos é mais tranquila. Embora eles mecham no celular de todo jeito, mesmo quando pedimos para que mantenham guardado.

(Diálogo com professores, 2019).

A fala do professor ao referir-se aos seus estudantes como "novos alunos", descrevendo-os como jovens conectados, nos direcionou para os estudos desenvolvidos por Queiroz (2015), ao apresentar a famosa frase de Mozart Neves Ramos, em que "o Brasil ainda tem uma escola do século XIX, professores do século XX e alunos do século XXI". A autora discorre como alguns professores continuam vendo a sala de aula como algo à parte, não se permitindo inovar, enquanto os alunos vivem um hiperativismo sócio-virtual cada vez mais fluído e instável.

De acordo com Bauman (2000), o modo de conviver e agir dos sujeitos mudou gradativamente em detrimento do uso das tecnologias, através das quais as informações podem ser reduzidas a um clique. Para Queiroz (2019), embora a escola tenha inserido equipamentos tecnológicos (computadores, lousas digitais, Datashow), isso não tem sido suficiente diante do notável desinteresse dos alunos nesse espaço. A escola impõe que desliguem seus celulares e os alunos são obrigados a adequarem-se as normas, permanecem sentados, ouvindo o professor falar sobre determinado assunto, enquanto sua mente anseia pelo fora, eles se desterritorializam no instante em que a aula inicia.

Alguns falam de motivação. Como motivar um grupo de prisioneiros encarcerados, sem terem feito nada de ilícito para ali estarem? Ou seja, como motivar alguém inocente que foi posto de castigo? Como fazer com que ele goste dali, se ali ele, não é?" Para tanto, precisamos discutir um pouco mais sobre a sociedade do século XXI e, em seguida, refletir um pouco sobre o que representa a escola diante dessa sociedade. Por último, não menos importante, divagar (de uma maneira geral) sobre o perfil dos jovens que fazem parte do contexto escolar e, em meio a tudo isso, onde se encontra a Matemática (QUEIROZ, 2019, p. 3).

Acredito que o objetivo dos estudos realizados por Queiroz (2019) não é ser contra o avanço tecnológico, mas nos fazer refletir enquanto professores ou alunos, o quanto a tecnologia hoje é presente e faz parte de nossas vidas. Embora pareça distante na realidade escolar, não é o aparato tecnológico em si que despertará o interesse dos alunos, mas a falta do desejo do aluno nesse espaço. A reprodução é enfadonha, a informação pela informação é desinteressante, a informação está a um click e atualmente o saber não é exclusivo da escola. A matemática ensinada na escola só faz sentido dentro da sala de aula, só se tem contato com a matemática ensinada na escola pelo professor, sua motivação tem somente a necessidade de se tirar uma boa nota diante da temida reprovação, motivos poucos convincente e desmotivadores.

Entretanto, é na escola que este indivíduo (aluno) precisa organizar formalmente os conhecimentos adquiridos, com o objetivo de acrescentar novos conhecimentos e aplicá-los em outros procedimentos, ou ainda modificar os já existentes (QUEIROZ, 2016). É preciso deixar claro para o aluno que o conhecimento é peça chave na solução de problemas 
científicos, tecnológicos e sociais. Com toda a facilidade que a internet e as tecnologias trouxeram, e ainda trarão, é preciso questionar o papel da escola em meio a essa revolução, não apenas aceitar e achar que não vale a pena mudar porque sempre foi dessa maneira.

\section{Hiperativismo Pedagógico}

Os estudos sobre o hiperativismo sócio virtual (QUEIROZ, 2019) me inspirou a perguntar: O que se espera do professor na contemporaneidade? Mais ainda, quais os efeitos para o docente diante desse hiperativismo sócio virtual que atinge nossos alunos na sala de aula? Algumas repostas relatadas pelos professores apontam a construção de uma nova verdade, a qual estabelece um caminho desejado para tornar a matemática mais interessante, ou motivadora. A verdade que as abordagens didáticas/metodológicas são o caminho para reverter os desafios de ensinar e aprender matemática tem sido consolidada.

Esclarecemos que estudar a prática discursiva segundo Foucault (2008) não significa ser contra ou favor dessas verdades, mas pensar o discurso como uma rede, ferramenta que permite concebê-lo como uma construção cultural e social de cada tempo causador de efeito no sujeito, principalmente por sua função criadora de sentido e significados. Investigar as prescrições e métodos presentes no ensino e na aprendizagem, não nos obriga a assumir uma posição contra ou a favor, embora consideramos que elas possibilitam um exercício de pensamento sobre o que está sendo realizado e o que se pode fazer a partir dessas.

O discurso da matemática difícil ganha um novo direcionamento. "O desejo tem sido a substituição da matemática limitada e difícil pela matemática acessível a todos, esse movimento tem produzido uma discursividade de produção docente por acreditar que esse conseguirá modificar o panorama de acordo com sua prática" (COSTA; QUEIROZ, 2019, p. 2). Frente a isso, tem-se os documentos enfatizando a necessidade de reverter os métodos expositivos, centrados em procedimentos mecânicos e responsabilizados pelos fracassos. Ainda, temos os "novos alunos", os quais a escola vem tentando se adequar.

O contexto de ensinar e aprender matemática é um campo amplo, temos investigações que "[...] solicitam domínio compreensivo de um vasto horizonte de conhecimento, como horizontes da Psicologia, da História, da Filosofia... e certamente, da matemática" (BICUDO, 1993, p. 20). Nesse campo, dedica-se a estudar questões relativas tanto ao ensino (suas técnicas, tendências, os docentes, a formação, etc.) quanto à aprendizagem (cognição, discente, etc.), assim como a relação entre o ensino e a aprendizagem (contrato didático, saberes, etc.) de Matemática. Essas questões vêm progressivamente ampliando suas discussões no meio acadêmico. Nesse viés, tem sido desenvolvidas inúmeras pesquisas, com ênfase em questões cognitivas, epistemológicas e sociais (inter e intrapessoal) que perpassam o ensino e aprendizagem, com o intuito de contribuir para um processo mais efetivo e significativo.

Dessa maneira, circulam muitas pesquisas validadas em determinar as emergências de "atualizações" necessárias ao ensino de matemática, constituindo-se a verdade nesse campo. Desse modo, podemos entender que o discurso sobre o ensino da Matemática, constituído por diversos enunciados: "é importante o aluno ser protagonista", "como despertar o interesse dos alunos", "como tornar a matemática mais fácil", "novas metodologias são fundamentais", entre outros, esses enunciados pertencem ao mesmo campo, a uma mesma formação discursiva, remetendo a dificuldade e afirmando a cobrança para que algo seja feito quanto seu ensino. 
É possível perceber nas enunciações, uma exacerbada preocupação, por parte dos educadores, em promover a motivação e garantir o interesse do aluno por meio das práticas lúdicas. Cada vez mais são elaboradas estratégias, metodologias, didáticas com o objetivo de proporcionar ao aluno o prazer em estudar, para que ele tenha interesse e motivação em aprender, promovendo assim, como apontam Veiga-Neto e Saraiva (2009), satisfações imediatas (SARTORI, DUARTE, 2015, p. 895).

Como vimos anteriormente, essas produções ganham base e autorização perante a materialização desses discursos presentes nos documentos curriculares, apresentam um caminho belo a ser percorrido, sem contradições e aparentemente sem conflitos. Mas, como isso é possível? É possível, pois os documentos são elaborados por especialistas, que "sabem" o que é melhor para os professores, para os estudantes e para a comunidade. Os professores ocupam uma posição de executor das propostas fornecidas pelos especialistas na trama discursiva, apresentando como um dos problemas centrais, a formação deficitária do professor.

É justamente nessa trama da formação insuficiente do professor que se consolida a importância desses documentos norteadores e, por vezes, de não participação do mesmo em sua elaboração. Oliveira (2006, p. 95), em seu estudo sobre a revista Nova Escola, dispositivo utilizado por muitos professores, aponta que os enunciados e discursos sobre a matemática escolar "[...] insinuam a ideia de professor que não sabe esta disciplina e tampouco sabe ensiná-la". A revista, desse modo, serve para sanar as dúvidas, tornar mais fácil e explicar determinados conteúdos indicados pelos próprios leitores, orientando ações pedagógicas lúdicas e buscando modificar a postura dos professores e melhorar a qualidade do ensino.

Essa formação deficitária tem mais força principalmente em sua fase inicial. Mattos (2013) descreve esse momento como uma transição de aluno para professor, em que ocorrem múltiplas aprendizagens e conhecimento profissional para que o professor consiga sobreviver diante dos choques e da descoberta da profissão escolhida, momento marcante considerado importante e, ao mesmo tempo, difícil. Entretanto, os professores mais antigos também demonstram dificuldades e buscam soluções diante do novo público que a escola tem recebido.

Para Mattos (2013), os professores iniciantes constroem suas práticas em meio aos discursos de diferentes formadores e os mais diversos autores que seus professores tiveram acesso, relacionando com suas vivências pessoais, crenças, e posteriormente com as experiências profissionais, constituindo, assim, suas representações de ser um bom professor, idealizando uma postura docente, o que torna conflitante, pois geralmente o primeiro contato ocasiona um choque de realidade. Nessa etapa de sua formação, são convidados a "[...] despirem-se de suas identidades estudantis e vestirem-se com a identidade de professores" (LENZI, 2008, p. 84).

Ao serem perguntados pelas suas escolhas pela licenciatura e inspirações em relação à sua conduta e prática, também foi pedido que os participantes descrevessem sua primeira aula como professor, assim tivemos as seguintes descrições:

Pesquisadora: Sua conduta docente, práticas, atitudes, está relacionada a alguma lembrança ou inspiração de professores, colegas de trabalho, obras literárias, filmes, relacionados à docência, de como ser um bom professor?

Hi-tech: Eu não gostava de matemática até o nono ano, tive traumas e travei na 
disciplina, mas uma professora do nono ano, com seu ensinar (metodologia), fez com que me inspirasse no professor que sou hoje.

Reflexivo: Eu sempre gostei de matemática, mas o que me fez optar por ser professor de matemática, foi meu professor de matemática da época de Ensino Fundamental e Médio.

Pesquisadora: Vocês lembram de suas primeiras aulas como professor? Poderiam descrevêlas?

Hi-tech: Sim, foi uma aula numa turma de Ensino Médio com 60 alunos. Era uma

turma do 1 o ano A, estava muito nervoso e não tinha dado tempo de preparar a aula direito, pelo motivo de ter sido chamado para trabalhar 11 horas da manhã e começava a trabalhar 13 horas da tarde, no mesmo dia. Tive que me impor e ser bem severo nesse dia.

Pesquisadora: Foi parecida com a aula da professora que você se inspirou?

Hi-tech: (risos) de jeito nenhum.

Reflexivo: A minha também não... A minha foi assim, eu fui substituir uma aula, numa escola particular, e eu preparei, não lembro se era oitavo ou nono ano. Acho que era nono, porque eles estavam vendo bháskara e eu preparei tudo bonitinho, escrevi tudo direitinho e quando fui lá, foi a pior aula que já dei na minha vida. Porque eu não consegui passar o conteúdo de uma maneira suscinta. Só ficava falando e ficava falando, estava muito nervoso e os alunos perceberam também e não ajudaram muito, então, eu acho que a primeira aula, não vou dizer nem para esquecer, mas... foi uma experiência ruim.

Pesquisadora: Foi parecida com a aula do professor que você se inspirou?

Reflexivo: Não!

(Diálogo com professores, 2019).

Os professores, em sala de aula, se veem rodeados de desafios. Segundo Queiroz (2019, p. 11, grifo do autor) "Quando se termina uma graduação em Matemática, alguns aderem à ideia de que estão 'formados', como se antes estivessem em um estado disforme, passando-nos a ideia de que o diploma tem um fim em si mesmo, e com sua obtenção, estão prontos. Mas, prontos para o quê?" Os licenciandos veem-se sem saída e passam a reproduzir o que lhe fora ensinado, mesmo percebendo que algo não está funcionando.

Conforme descrito por Aurich e Pinho (2012), encontram-se em meio a tecnologia da internet, textos, livros, revistas, artigos, publicações online, impressas, dicas e ditos infalíveis para se constituir um bom professor. Embora, esses materiais não representem uma novidade na educação matemática atual, mas uma reatualização para a contemporaneidade.

De outro lado, estão os futuros professores de matemática em sua (de)formação inicial, esperando ansiosamente por aquelas fórmulas salvadoras (por pensarem que delas precisariam) que lhes garantam sucesso na profissão e um bem-estar resultante do cumprimento de tais prescrições. Isso requer, de nossa parte, um andar em outra mão, um pensamento diverso das verdades discursivas pedagógicas que lhe constituem, pois entendemos que pensar fora desse campo prescricional, de tudo o que "deve" e "pode" o professor, possui relação não só com seus saberes, mas também com suas práticas, suas formas de ação e suas respostas éticas, que Ihe podem dar possibilidades estéticas de ser (AURICH; PINHO, 2012, p. 6).

De acordo com Aurich (2017), mesmo não percebendo, a aula está dada antes mesmo de começar. A preparação de uma aula transborda de coisas pré-aula. O professor pensa que muitas decisões foram tomadas por si, mas nem desconfia que foi constituído por discursos, moral e verdades que lhe envolvem e transitam nos espaços da universidade e da escola. Essas 
considerações se estabelecem facilmente diante do ensino de matemática, considerado problemático.

Oliveira (2006) alerta, pois o que deveria ser considerado como troca de experiência, através de artigos sobre matemática escolar, ou relatos de experiências, passa a ser a prescrição de diferentes estratégias sobre como ensinar tal conteúdo, contando todas as intervenções necessárias indicadas para dar certo. Esse intercâmbio, ao nosso ver, é importante, porém, falha quando parecem totalizar essas práticas, enfatizando apenas a eficácia de suas atividades, contribuindo para uma compreensão de um modelo infalível, que caso não venha a funcionar, justifica-se na compreensão de que o professor não aplicou de maneira correta ou foi desatento a alguma etapa, desconsiderando todas as outras variáveis envolvidas nesse processo.

Com isso, passamos a pensar sobre o hiperativismo pedagógico vivenciado pelos docentes, em que encontramos Oliveira (2006) fazendo uma rápida e única menção sobre o conceito no espaço de formação de estudantes e professores que não têm servido à produção de sentido ou experiência, mas apenas de opnismo e de divulgação de informações e descrições, fruto de uma racionalidade didática qualquer.

Outra única menção ao termo aparece no estudo sobre atividades na Educação Infantil, desenvolvido por Rech (2004, p. 116), no qual a autora apresenta que "[...] se as professoras assim agissem, estariam menos vinculadas a métodos prescritos de ensinar e tornar-se-iam observadoras e intérpretes das diversas experiências vivenciadas pelas crianças.". O foco seria na possibilidade de aprender os processos cognitivos das crianças, estando menos preocupadas com o hiperativismo pedagógico que pouco contribui para a produção de experiências.

Segundo Duarte e Sartori (2017, p. 23), "o estudo dessas mudanças, sucedidas em todo mundo capitalista e atreladas principalmente às inovações tecnológicas, também contribui para colocar em questão as práticas escolares, pois estas são essenciais para o entendimento da derrocada disciplinar". Nesse sentido, estão a serviço apenas do opnismo e da divulgação de informações, inclusive, na produção e venda de materiais destinados aos professores para tornar suas aulas mais interessantes. Considerando todo esse hiperativismo pedagógico e essa exacerbada preocupação quanto ao uso de novas técnicas e novos métodos de ensino, percebo que há muito mais a ser investigado e questionado. Essa visão tem contribuído para a compreensão do ensino de matemática reduzido a aplicação de métodos, desconsiderando toda pluralidade e contexto sociocultural.

Por em dúvidas essas questões geraram certa angústia, por vezes, não o consegui explicá-lo por colocar em choque uma possível racionalidade de um caminho a ser seguido para ensinar matemática. Ato que exigiu coragem, senti o estranhamento de uma turma em um congresso, onde todos apresentavam orgulhosamente uma prática que deu certo em suas turmas e, em seguida, debati sobre essa fabricação docente originada pela discursividade do fazer pedagógico e me vi bombardeada sobre qual o caminho então a ser seguido. De fato, estamos sempre procurando "o" caminho para ensinar mais e melhor, mas talvez ele não exista, isso não significa que devamos permanecer onde estamos. Ao realizar essa pesquisa, busquei mais que respostas ou resultados.

\section{Considerações}

Esforçar-se para rever as coisas de modo crítico não significou romper completamente as barreiras e desafios existentes, significou um agenciamento e uma possibilidade, 
questionamentos, descontinuidade sobre verdades tão bem estabelecidas no âmbito educacional. Ao analisar os resultados, fomos percebendo o quanto a prática docente é um campo amplo, entrelaçado com tantos outros fatores que o compõem, entre formação inicial, continuada, fatores históricos, culturais, sociais, relações de saber, poder e subjetivação, que organizam e controlam os mais diversos mecanismos, como currículo, comportamentos, hábitos e crenças.

Os dados apresentados não estão focados apenas nas práticas do professor de matemática, apresentam aspectos mais amplos, podendo contribuir para outras áreas. Pensar em constituir-se professor através desse jogo de verdades instaurado na sociedade é pensar em si como professor, e pensar no outro como aluno. A sala de aula é um território de constituições de poder, mas também de resistências, a resistência dos alunos talvez seja um apontamento para que esse poder seja exercido adequadamente. Quanto mais identificarmos e questionarmos os discursos que norteiam a escola, a disciplina de matemática, mais poderemos contestá-los e transcendê-los, produzindo sentidos novos e consequentemente novos discursos.

Não se trata de visar a destruição ou a desmistificação dos discursos existentes, mas a produção de novos discursos, de modo que não contribuam para a restrição dos saberes desenvolvidos. A universidade como um espaço de produção e validação dos saberes pode e deve criar discursos, de modo a subjetivar o professor a desejar ser mais autônomo, professores que questionem o conjunto de saberes, poderes, discursos, a velocidade da escola, sua finalidade, de modo a criar maneiras capazes de tornar a experiência possível, discursos que valorizem o governar-se e o conhecer-se para tornar tudo isso possível.

Ao pesquisarmos somos movidos pelo desejo de resolver uma questão que nos parece problemática, durante a nossa constituição como pesquisador, vamos nos distanciando e desfamiliarizando das certezas e soluções práticas, passamos a enxergar a multiplicidade de variáveis que se encontram em cada campo. Desse modo, vamos compreendendo que não existe "a resposta", não existe um caminho salvífico, mas existem respostas, possibilidades, caminhos, sempre no plural, pois variam de acordo com seu tempo, seus espaços, seus sujeitos. "O professor deve parar de procurar receitas para salvar os alunos, mas pensar na prática educativa de forma diferente e pôr à prova tudo o que já está institucionalizado. Especialmente a prática de querer salvar o outro sem ele próprio praticar-se em devir" (CATTO, 2010, p. 43).

\section{Referências}

AURICH, Grace da Ré.; PINHO, Patrícia Moura. Jogos de verdade e o bom professor de matemática. In: SEMINÁRIO DE PESQUISA EM EDUCAÇÃO DA REGIÃO SUL, IX, 2012, Caxias do Sul - RS. Anais. Anped: Rio de Janeiro. v. 1, p. 1-19, 2012.

AURICH, Grace da Ré. Reescrita de Si: Invenção de uma Docência em Matemática. 2017. 152f. Tese (Doutorado) - Universidade Federal do Rio Grande do Sul, Faculdade de Educação, Programa de PósGraduação em Educação, Porto Alegre, 2017.

BATISTA, Fabio; BACCON, Ana Lúcia Pereira; GABRIEL, Fábio Antônio. Pensar a escola a partir de Foucault: uma instituição disciplinar em crise? Inter-ação, (UFG. Online). v. 40, p. 1-16, 2015.

BAUMAN, Zygmunt. Modernidade Líquida. Rio de Janeiro: Zahar, 2000. 
BICUDO, Maria Aparecida Viggiani. Pesquisa em Educação Matemática. Proposições, v. 4, n. 1, 1993.

BRÍGIDO. Edimar Inocência. Michel Foucault: Uma análise do poder. Rev. Direito Econ.

Socioambiental, Curitiba, v. 4, n. 1, p. 56-75, jan./jun. 2013.

CASTRO, Edgardo. Vocabulário de Foucault: um percurso pelos seus temas, conceitos e autores. Trad. de Ingrid Muller Xavier; revisão técnica de Alfredo Veiga-Neto e Walter Omar Kohan. Belo Horizonte: Autêntica, 2009.

CATTO, Cândida. Educação como subjetivação. Caderno pedagógico, Lajeado, v. 7, n. 2, p. 36-48, 2010.

COSTA, Luana Rafaela Silva; QUEIROZ, Simone Moura. O gostar de matemática: Discurso, desejo e marca. In: Maria Fernanda dos Santos Alencar; Marcelo Henrique Gonçalves de Miranda; Maria Fabiana da Silva Costa; (Org.). Educação, estado e diversidade: perspectivas e desafios. 1 ed. Recife: Editora UFPE, v. 5, p. 17-37, 2019.

DELEUZE, Gilles. O que é um dispositivo? In: Michel Foucault, filósofo. Trad. de Wanderson Flor do Nascimento. Barcelona: Gedisa, p. 155-161, 1990.

DELEUZE, Gilles. Conversações: 1972-1990. Rio de Janeiro: 34 ed., 2013.

DUARTE, Claudia Glavam.; SARTORI, Alice Stephanie Tapia. Foucault e Deleuze: provocações ao discurso da Educação Matemática. Perspectivas da Educação Matemática. Revista do Programa de Pós-Graduação em Educação Matemática da Universidade Federal de Mato Grosso do Sul (UFMS). v. 10, n. 22, 2017.

FISCHER, Rosa Maria Bueno. Foucault e a análise do discurso em educação. Cadernos de Pesquisa. Rio de Janeiro, n. 114, p. 197-223, nov. 2001.

FOUCAULT, Michel. A arqueologia do saber. 7 ed. Rio de janeiro: Forense Universitária, 2008.

FOUCAULT, Michel. A ordem do discurso: aula inaugural no Collège de France, pronunciada em 2 de dezembro de 1970/Michel Foucault. Trad. de Laura Fraga de Almeida Sampaio. 2 ed. São Paulo: Edições Loyola, 2013.

FOUCAULT, Michel. Microfísica do Poder. Rio de Janeiro: Graal, 2000.

FOUCAULT, Michel. Vigiar e Punir: nascimento da prisão. 30 ed. Petrópolis: Vozes, 2005.

LENZI, Giovana da Silva. Prática de ensino em educação matemática: a constituição das práticas pedagógicas de futuros professores de matemática. 2008. 140f. Dissertação (Mestrado) Universidade Federal do Rio Grande do Sul. Porto Alegre - RS, 2008.

MATTOS, Sandra Maria Nascimento. Ser bom professor de matemática: a visão de professores iniciantes. In: CEMACYC, I, Anais. República Dominicana, 2013.

In:http://funes.uniandes.edu.co/4239/1/MattosSerbomCemacyc2013.pdf. Acesso em 26 de fev. de 2019. 
OLIVEIRA, Claudio José. Discursos sobre a matemática escolar: um estudo a partir da Revista Nova Escola. In: Reunião Anual d Associação Nacional de Pós-Graduação e Pesquisa em Educação, XXX, 2007, Caxambu - MG. Anais. Rio de Janeiro: Anped, 2007. v. 1, p. 1 - 16.

OLIVEIRA, Claudio José. Políticas educacionais e discurso sobre matemática escolar: um estudo a partir da revista nova escola. 2006. 210f. Tese (Doutorado) - Universidade do Vale do Rio dos Sinos, Programa de Pós-Graduação em Educação, 2006.

QUEIROZ, Simone Moura. A educação em meio ao Hiperativismo sócio-cultural do mundo líquido. In: X ENCONTRO NACIONAL DE EDUCAÇÃO MATEMÁTICA, XII, 2016, São Paulo. Anais. São Paulo: SBEM, 2016. v. 1, p. 1-9.

QUEIROZ, Simone Moura. Sala de aula: sociedade de controle, comprismo e hiperativismo sociovirtual versus o cuidado de si. In: Maria Fernanda dos Santos Alencar; Marcelo Henrique Gonçalves de Miranda; Maria Fabiana da Silva Costa. (Org.). Formação de professores e processos de ensino e aprendizagem: práticas pedagógicas e contribuições das políticas públicas. 1 ed. Caruaru: UFPE, v. 6, p. 135-158, 2019.

QUEIROZ, Simone Moura. Movimentos que permeiam o devir professor de matemática de alguns licenciandos. 2015. 208f. Tese (Doutorado em Educação Matemática) - Instituto de Geociências e Ciências Exatas, Universidade Estadual Paulista, Rio Claro, 2015.

RECH, Ilona Patrícia Freire. A "hora da atividade" na educação infantil: um estudo a partir de um centro de educação infantil público municipal. 2004, 136f. Dissertação (Mestrado) - Universidade Federal de Santa Catarina: Florianópolis - SC, 2004.

SARTORI, Alice Sthephanie Tapia.; DUARTE, Claudia Glavam. Uma análise do discurso na perspectiva foucaultiana: As práticas lúdicas na Educação Matemática. Perspectivas da Educação Matemática. Revista do Programa de Pós-Graduação em Educação Matemática da Universidade Federal de Mato Grosso do Sul - (UFMS), v. 8, número temático, 2015.

VEIGA-NETO, Alfredo. Foucault \& a educação. 2 ed. 1 reimpressão. Belo Horizonte: Autêntica, 2007. 